\title{
An unusual case of monolobar Caroli's disease
}

\author{
ANTHONY J GOMES MD, ROBERT J BAILEY MD FRCPC
}

AJ GOMES, RJ BAILEY. An unusual case of monolobar Caroli's disease. Can J Gastroenterol 1994;8(3):185-188. A 27-year-old male with recurrent upper abdominal pain was found to have a suspicious mass in the right hepatic lobe. Right hepatectomy was performed. Pathological examination and further radiological evaluation proved this to be a focal form of Caroli's disease.

Key Words: Caroli's disease, Cholangiocarcinoma, Cholangitis, Intrahepatic duct dilation, Monolobar

\section{Cas inhabituel de maladie de Caroli monolobulaire}

RÉSUMÉ : Un homme de 27 ans souffrant de douleurs abdominales hautes récurrentes présente une masse douteuse au lobe hépatique droit. L'hépatectomie droite a été effectuée. L'examen pathologique et d'autres épreuves radiologiques confirment qu'il s'agit d'une forme localisée de la maladie de Caroli.

\footnotetext{
ARoli's disease is a rare biliary anomaly that usually involves the liver diffusely. In some cases, however, it may be focal and present as a suspicious mass within the liver. An unusual case of pure Caroli's disease with monolobar localization to the right hepatic lobe - diagnosis was made following right hepatic lobectomy - is described, followed by a review of the relevant literature.
}

\section{CASE PRESENTATION}

A 27-year-old Caucasian male presented with a nine-year history of intermittent epigastric pain not associated with fever or jaundice. Physical examination was normal. Liver function tests were within normal limits. An ultrasound of the liver suggested a mass in the right lobe of the liver. Computed tomography (CT) scan of the abdomen revealed a $13 \times 11 \times 11 \mathrm{~cm}$ mass in the

Departments of Medicine (Gastroenterology) and Surgery, Royal Alexandra Hospital, Edmonton, Alberta

Correspondence: Dr AJ Gomes, University of Alberta Hospitals, Department of Surgery, 2D1.02 Mackenzie Centre, 8440-112 Street, Edmonton, Alberta T6G 2B7. Telephone (403) 454-3541

Received for publication August 15, 1993. Accepted November 15, 1993

posterior segment of the right lobe (Figure 1). Multiple internal areas of attenuation were noted, suggesting either dilated biliary radicals or focal areas of necrosis. Normal vascular structures were displaced anteriorly and medially. The kidneys and spleen were normal. It was felt that the mass was a primary hepatic neoplasm, either hepatoma or fibrolamellar carcinoma. A hepatic angiogram failed to yield additional information.

A laparotomy and right hepatic lobectomy were performed. Findings included a palpable mass in the superior portion of the right lobe, but the liver surface appeared grossly unremarkable.

Pathological examination revealed an area of thickening within the right lobe. Incision into this area revealed multiple dilated channels grouped in an area approximately $8 \mathrm{~cm}$ in diameter (Figure 2). Microscopically, the portal tracts were enlarged, with dilated cystic bile ducts.

These ducts were lined by a single layer of columnar mucinous cells with some papillary infoldings (Figure 3). Some ducts contained large biliary concretions. The remainder of the parenchyma showed mild steatosis only. These findings were compatible with a diagnosis of Caroli's disease, focal type, 


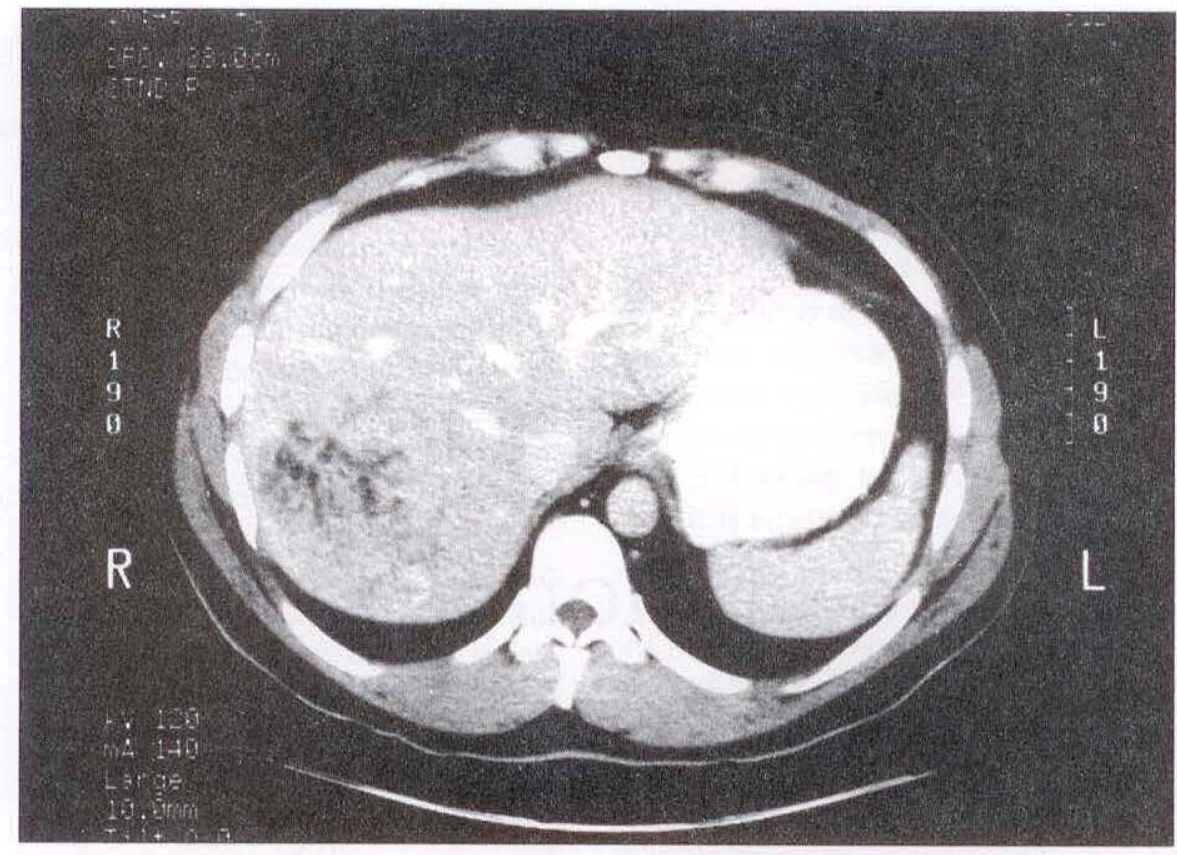

Figure 1) Augmented computed tomography scan of the upper abdomen showing a large inhomogeneous mass within the posterior segment of the right lobe of the liver displacing normal vascular structures

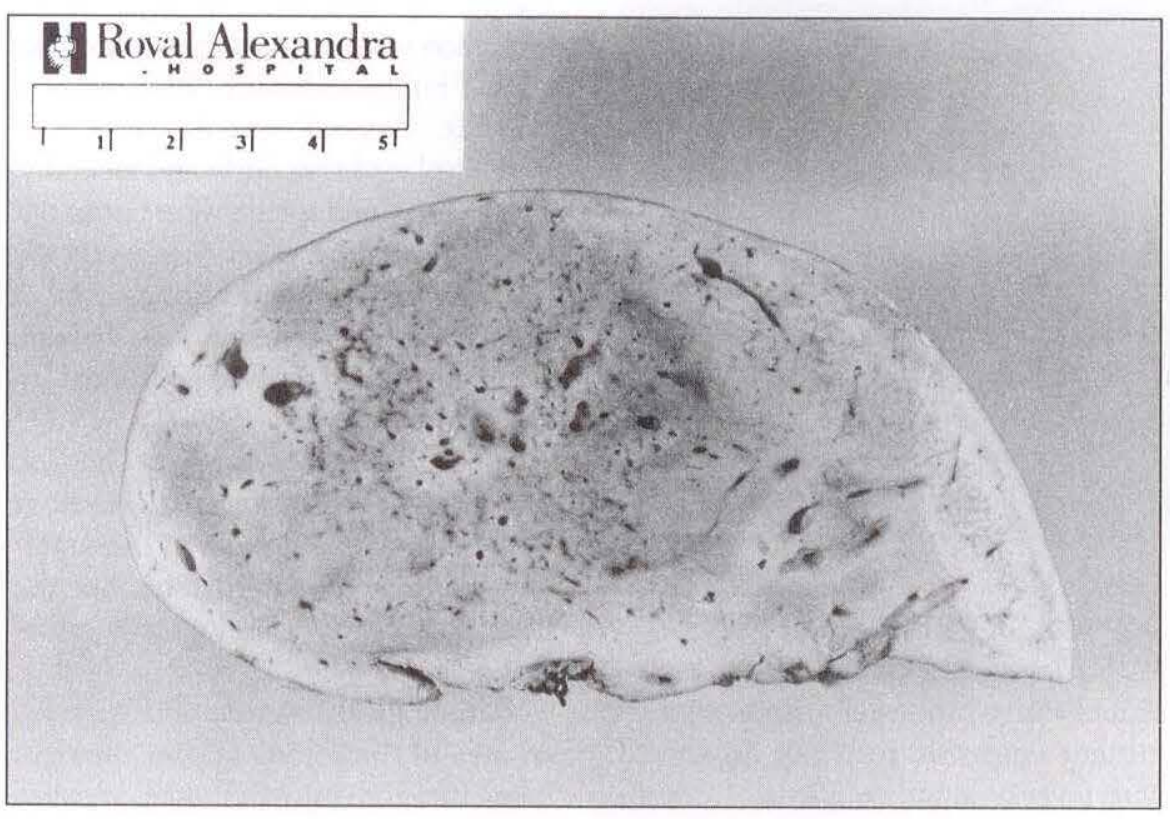

Figure 2) Cut section (gross) of the resected right hepatic lobe showing cystically dilated bile ducts

involving the right lobe of the liver. The patient made an uneventful recovery, and was discharged home on the 11th postoperative day. An endoscopic retrograde cholangiogram (ERCP) six months later revealed a normal intraand extrahepatic biliary system, with no evidence of remaining segmental duct dilation (Figure 4). The patient has been asymptomatic since surgery.

\section{DISCUSSION}

Caroli's disease $(1,2)$ is a rare condition characterized by dilation of the segmental intrahepatic bile ducts. It is congenital, and appears to be inherited in an autosomal recessive fashion (2-4).

The etiology of this condition is unknown, but has variously been attributed to embryological hepatic vascular occlusion (5), failure of resorption of the primitive biliary ducts (6) and inequality in the rate of growth between embryological liver connective tissue and biliary epithelium (7).

Caroli's disease appears to be just part of a spectrum of developmental abnormalities of the biliary tree $(8,9)$. This spectrum includes choledochal cysts, which accompany intrahepatic duct dilation in 22 to $53 \%$ of cases $(9,10)$, and congenital hepatic fibrosis in $35 \%$ of cases (9). Nearly one-third of patients with Caroli's disease have both (9).

Two forms of Caroli's disease have been described (2). The first - the simple or 'pure' form - is not associated with congenital hepatic fibrosis and is uncommon (13\%) (9). The second form is 'periportal fibrosis associated type', which is linked to congenital hepatic fibrosis, cirrhosis and portal hypertension (2).

The cystic biliary radicals most commonly involve the entire liver. Boyle et al (11) found monolobar involvement in 34 of 180 known cases of Caroli's disease and noted that monolobar involvement may be more common in the pure form. The right lobe is rarely affected in monolobar disease (8\%).

Renal anomalies, most commonly medullary sponge kidney and dilation of collecting ducts, are common, and in the pure form of the disease are present in 60 to $80 \%$ of cases (11).

Our patient appears to have had the less common pure form of Caroli's disease, with rare monolobar localization to the right hepatic lobe. In addition, there was no evidence of other biliary tract or renal anomalies.

In the pure form of Caroli's disease, biliary stasis leads to intrahepatic calculi and infection. In $80 \%$ of cases, symptoms begin before age 30 years (10). Most commonly, recurrent fever, abdominal pain and, occasionally, mild jaundice are presenting features. Physical examination may reveal tenderness of hepatomegaly. Laboratory investigations are generally within normal limits, apart from a leukocytosis during attacks (2). Uncommonly, patients with associated hepatic fibrosis may present with complications of portal hypertension. Migration of intrahepa- 
tic stones may result in obstructive jaundice or pancreatitis $(11,12)$. Recurrent cholangitis characterizes the course of disease, and patients eventually die as a result of septic complications (2).

This malformation has only relatively recently been recognized, and missed diagnosis is common. Even when the diagnosis is made, the delay from onset of symptoms is between four and 12 years $(11,13)$. Often the diagnosis is made after multiple abdominal explorations, often with cholecystectomy and common bile duct exploration (10). With the advent of ultrasound and CT, however, the diagnosis is now more commonly made noninvasively (14). The monolobar form of Caroli's disease is diagnosed preoperatively in $27 \%$ of patients, most commonly by ERCP or CT scanning (11). In our case, the diagnosis was not entertained preoperatively.

No effective, definitive medical therapy exists for Caroli's disease $(11,14)$. Chenodeoxycholic acid has been recommended for patients with documented stones in Caroli's disease, and has been used successfully for dissolution following incomplete liver resection $(15,16)$,

Traditionally, surgery has consisted of bilioenteric anastomoses to improve drainage and aid clearance of common duct calculi (10). This, however, often results in incomplete decompression because the ectatic intrahepatic ducts often have stenotic segments $(10,13)$. External drainage has proven to be inadequate, and other surgical procedures are often necessary (10). If Caroli's disease is localized to a segment or lobe, hepatic resection is the procedure of choice; it invariably results in complete resolution of symptoms $(11,14,17)$.

Caroli's disease is complicated by cholangiocarcinoma in the affected ducts in up to $7 \%$ of cases $(12,13)$. $\mathrm{Pa}$ tients with cholangiocarcinoma tend to be older (mean 48 years of age) than those presenting with cholangitis (12). Epithelial dysplasia has been noted in resected cysts, supporting the premalignant nature of the lesion (18). In addition, malignant degeneration has been

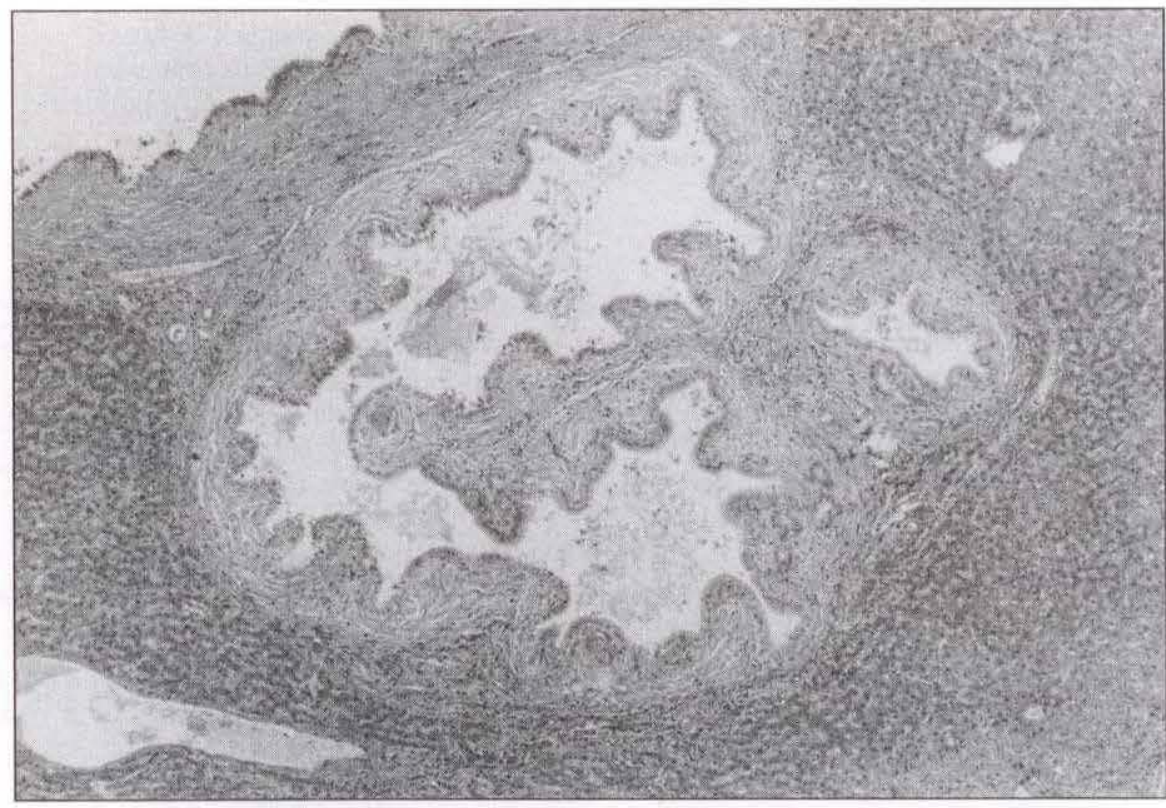

Figure 3) Low power photomicrograph of a dilated bile duct with papillary infoldings and biliary concretions within the lumen

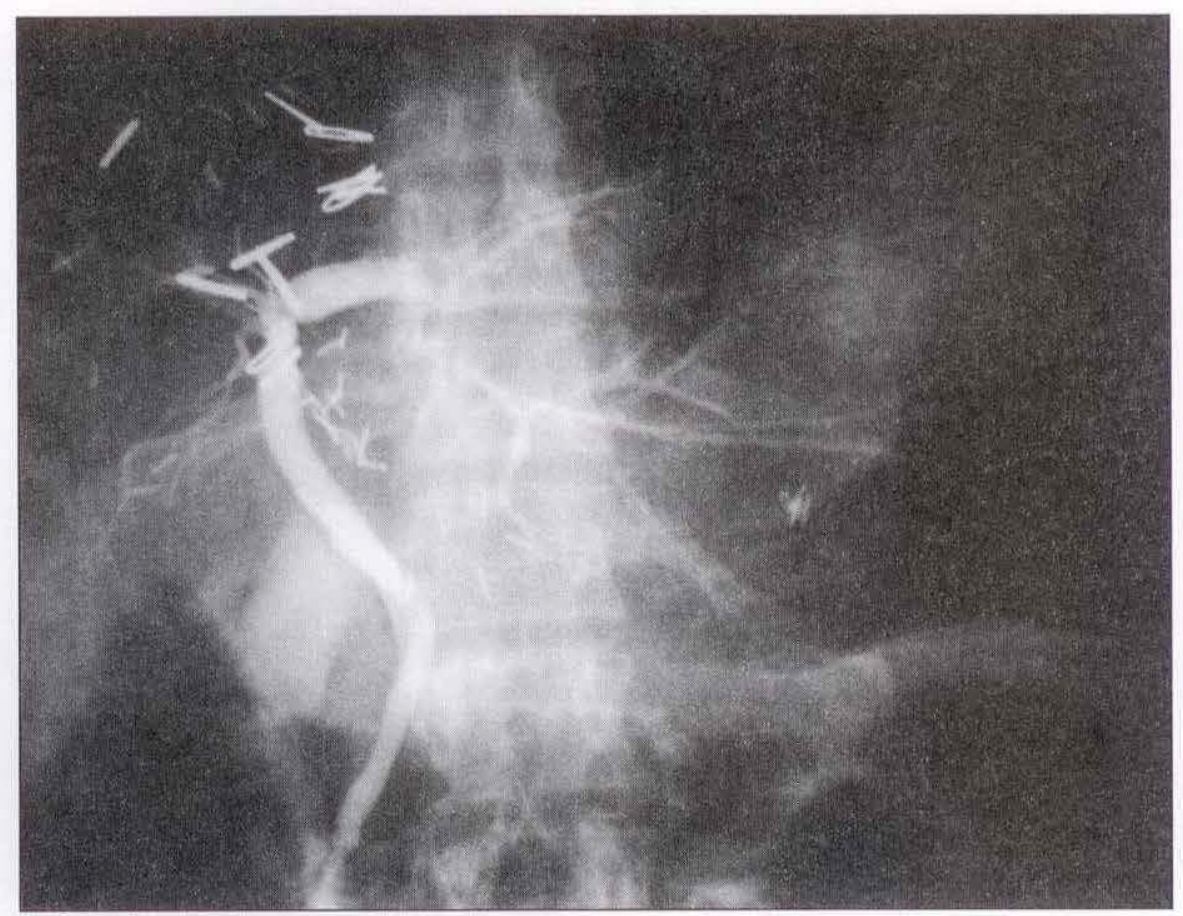

Figure 4) Postoperative endoscopic retrograde cholangiogram confirming the absence of dilated biliary ducts in the remaining liver

shown to occur in cystic areas despite adequate drainage $(12,19)$. This further reinforces the importance of early complete resection of symptomatic lesions when feasible.

In the presented patient, right lobectomy was performed for a suspicious liver mass. The patient's symp- toms remitted, and the future risk of cholangiocarcinoma should be reduced markedly.

ACKNOWLEDGEMENTS: The authors acknowledge the assistance of Drs SF Cox and DR Maclean in the preparation of this manuscript. 


\section{REFERENCES}

1. Caroli J, Soupault R, Kossakowski J, et al. La dilatation polykystique congenitals des voies biliares intrahepatiques. Essai del classification. Semin Hop Paris 1958;34:488-95.

2. Caroli J. Diseases of the intrahepatic biliary tree. Clin Gastroenterol 1973;2:147-53.

3. Blyth H, Ockenden B. Polycystic disease of kidney and liver presenting in childhood. J Med Genet 1971;8:257.

4. Hoglund M, Muren C, Schmidt D. Caroli's disease in two sisters, diagnosis by ultrasonography and computed tomography. Acta Radiol 1989;30:459-62.

5. Doppman JL, Dunnick NR, Girton M, et al. Bile duct cysts secondary to liver infarcts: Report of a case and experimental production by small vessel hepatic artery occlusion. Radiology 1979;130:1-5.

6. Jorgensen M. A stereological study of intrahepatic bile ducts. Acta Pathol Microbial Scand 1974;82:21.
7. Nakanuma Y, Teraada T, Ohta G, et al. Caroli's disease in congenital hepatic fibrosis and infantile polycystic disease. Liver 1982;2:346.

8. Serejo F, Velosa J, Carneiro de Moura $\mathrm{M}$, et al. Caroli's disease of the left hepatic lobe associated with hepatic fibrosis. J Clin Gastroenterol 1988;10:559-64.

9. Barros JL, Polo JR, Sanabia J, et al. Congenital cystic dilatation of the intrahepatic bile ducts (Caroli's disease): Report of a case and review of the literature. Surgery 1979;85:589-92.

10. Watts DR, Lorenzo GA, Beal JM. Congenital dilatation of the intrahepatic biliary ducts. Arch Surg 1974;108:592-8

11. Boyle MJ, Doyle GD, McNulty JG. Monolobar Caroli's disease. Am J Gastroenterol 1989;84:1437-44.

12. Dayton MT, Longmire WP, Tompkins RK. Caroli's disease: a premalignant condition? Am J Surg 1983;145:41-7.
13. Tandon RK, Grewal H, Anand AC, et al. Caroli's syndrome: A heterogeneous entity. Am J Gastroenterol 1990;85:170-3.

14. Nagasue N. Successful treatment of Caroli's disease by hepatic resection. Report of six patients. Ann Surg 1984;200:718-23.

15. Heymsfield S. Cystic dilatation of the intrahepatic biliary tree (Caroli's disease): a suggested treatment. Gastroenterology 1973;64:663.

16. Roda E, Sama C, Festi D, et al. Caroli's disease. Am J Gastroenterol 1979;71:621-6.

17. Ramond MJ, Huguet C, Danan G, et al. Partial hepatectomy in the treatment of Caroli's disease. Dig Dis Sci 1984;29:367-70.

18. Fozard JB, Wyatt JI, Hall RI. Epithelial dysplasia in Caroli's disease. Gut 1989;30;1150-3.

19. Todani T, Tabuchi K, Watanabe Y, et al. Carcinoma arising in the wall of congenital bile duct cysts. Cancer 1979;44:1134-41. 


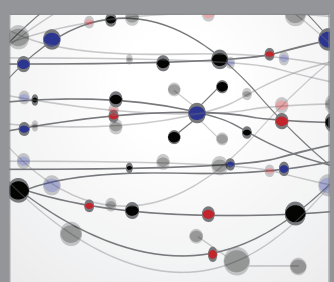

The Scientific World Journal
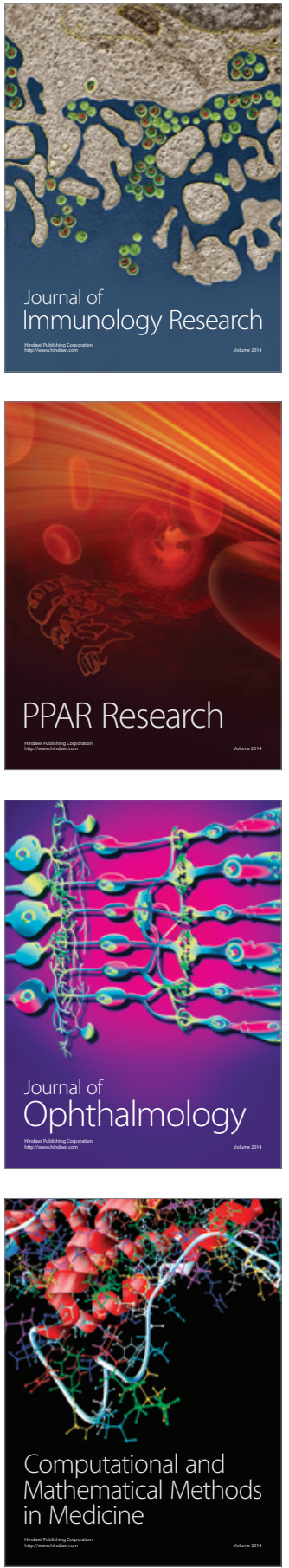

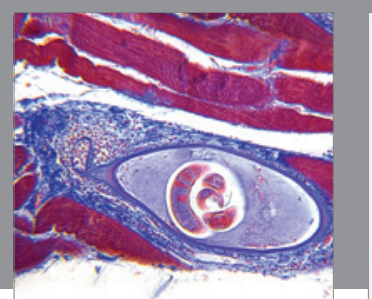

Gastroenterology Research and Practice

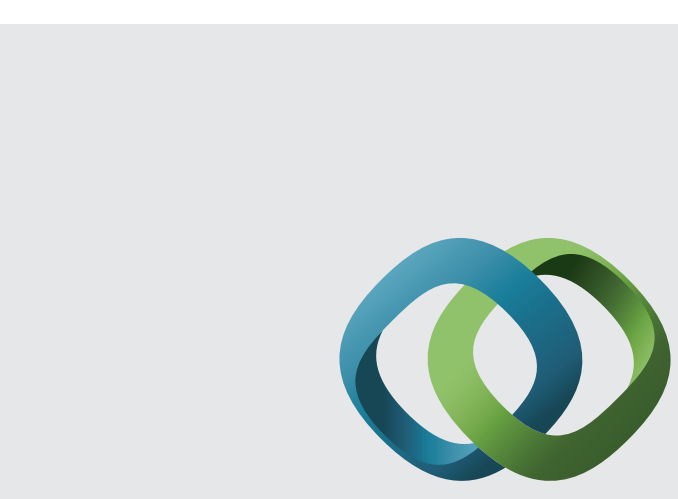

\section{Hindawi}

Submit your manuscripts at

http://www.hindawi.com
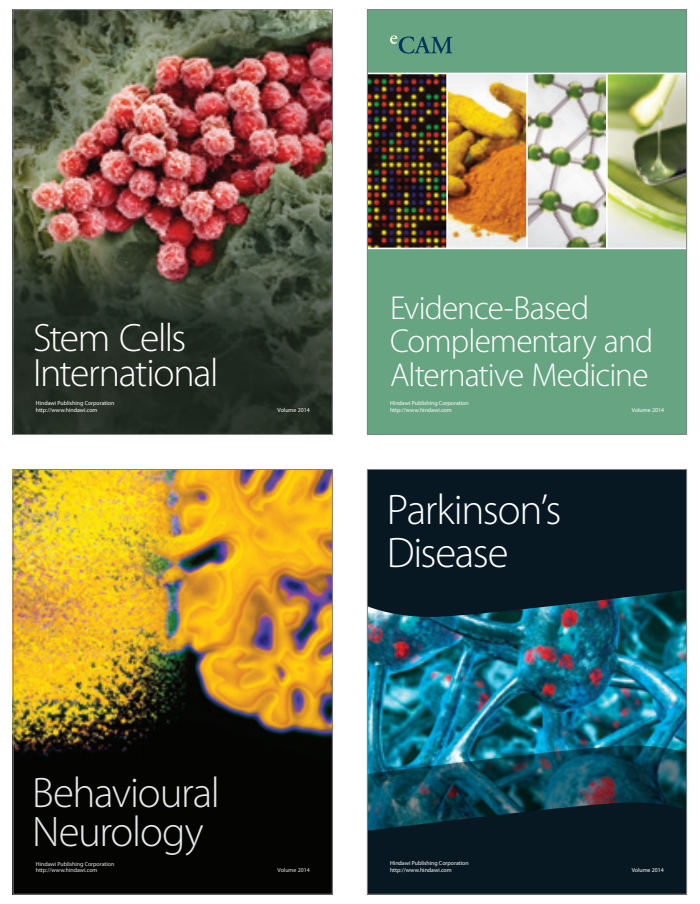
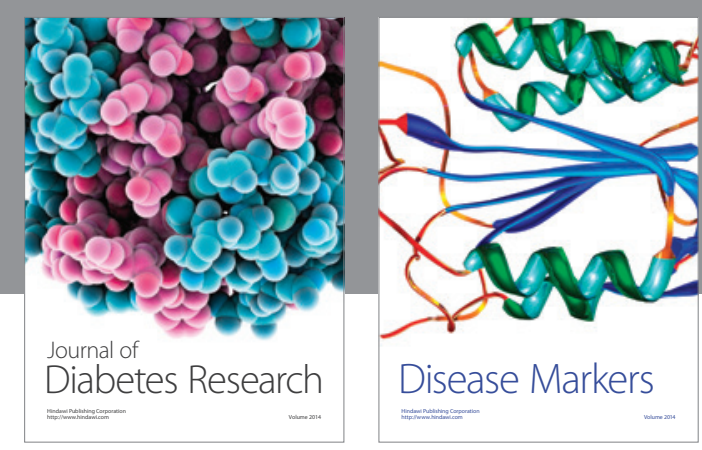

Disease Markers
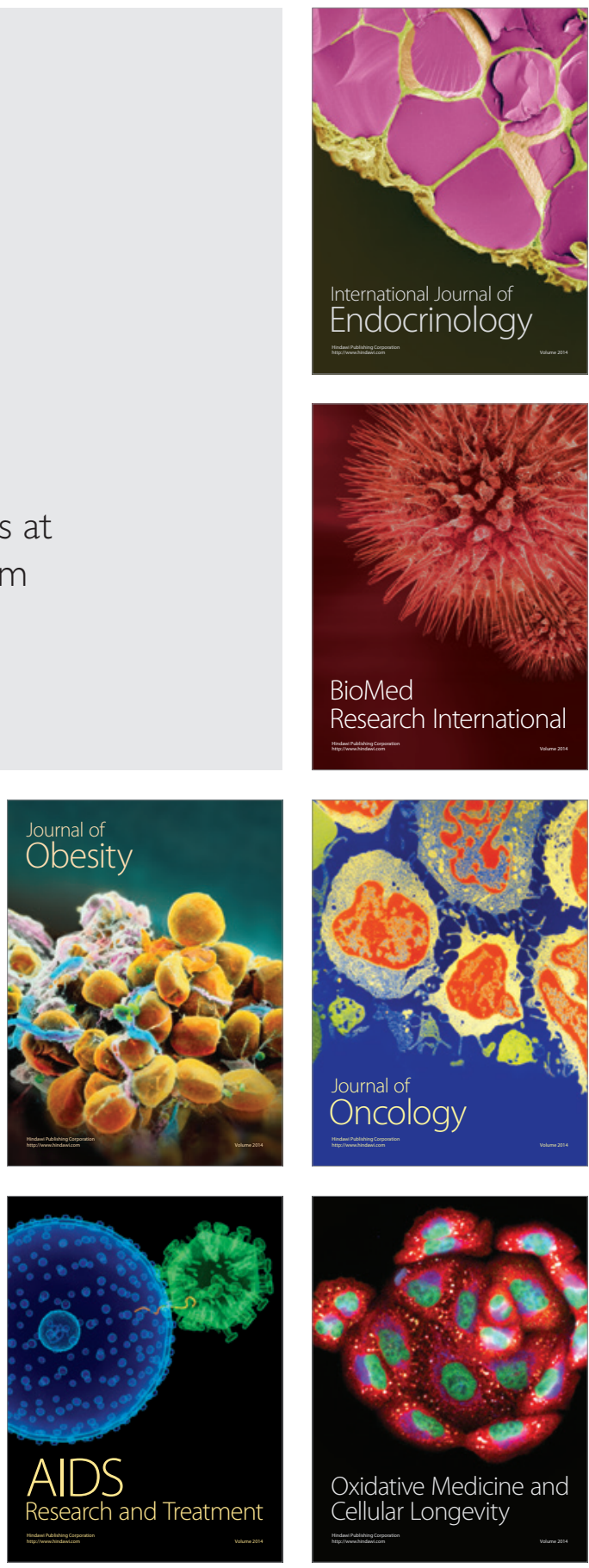